\title{
PERTUMBUHAN DERMATOFITA DAN JAMUR LAIN PENYEBAB TINEA PEDIS PADA PETANI MENGGUNAKAN MEDIA BEKATUL
}

\author{
Mujahidah Basarang ${ }^{1)}$, Tuty Widyanti'1), A. Fatmawati' ${ }^{1)}$, Nurhikmah ${ }^{1)}$ \\ 1) Politeknik Kesehatan Muhammadiyah Makassar \\ Alamat korespondensi: mujahidahbasarang@yahoo.com
}

\begin{abstract}
Abstrak
Bekatul adalah lapisan dari beras yang terlepas dari proses penggilingan gabah/padi. Bekatul mengandung karbohidrat sebanyak 84,36\% juga mengandung kalsium, magnesium, mangan, zat besi, kalium, dan natrium yang merupakan salah satu sumber energi utama dalam pertumbuhan dan perkembangan jamur dan nitrogen yang kompleks. Sehingga bekatul dapat digunakan sebagai media alternatif untuk mengisolasi jamur penyebab penyakit infeksi seperti Tinea pedis. Tinea pedis merupakan dermatofitosis pada kaki, terutama pada sela-sela jari kaki dan telapak kaki yang disebabkan oleh bermacam-macam jenis jamur yaitu Tricophyton rubrum, Tricophyton mentagrophytes dan Epidermophyton floccosum. Tujuan dari penilitian ini adalah untuk menyetahui media bekatul dapat digunakan untuk menumbuhkan jamur penyebab Tinea pedis dan jamur penyebab tinea pedis pada sela jari kaki petani. Metode yang digunakan adalah eksperimen laboratorik dengan menggunakan teknik pengambilan sampel secara purposive sampling, hasil penelitian ditemukan bahwa petani di kabupaten gowa yang secara klinis mengalami infeksi jamur adalah 10 orang. Dengan rincian 1 orang terinfeksi jamur penyebab primer dan 9 orang terinfeksi jamur penyebab sekunder. Jenis jamur penyebab yang menginfeksi yaitu Tricophyton interdigitale, Aspergillus flavus, Mucor circinelloides, Aspergillus fischeri dan Khamir. Berdasarkan penelitian ini dapat disimpulkan bahwa bekatul dapat digunakan untuk pertumbuhan jamur dan 1 orang petani terinfeksi jamur penyebab Tinea pedis yaitu jamur Tricophyton interdigitale.
\end{abstract}

Kata kunci: Bekatul, Tinea pedis, Petani

\section{PENDAHULUAN}

Dermatofita merupakan golongan jamur yang memiliki kemampuan melekat pada keratin dan mencerna keratin sebagai sumber nutrisi untuk bertahan (Magdalena, M. 2018). Pada umumnya Jamur sangat erat hubungannya dengan kehidupan manusia, mikrofungi ini dapat hidup di udara, tanah, air bahkan kulit adalah golongan dermatofita (Amanah et al. 2015). Efek yang ditimbulkan secara subjektif bervariasi mulai dari keluhan sampai dengan rasa gatal yang hebat dan rasa nyeri bila ada infeksi sekunder (Siregar, 1995 dalam rahmayani, 2011).

Pravalensi penyakit jamur di Indonesia sangat tinggi, beberapa penelitian telah dilaporkan bahwa Dermatofitosis yang terjadi berbagai rumah sakit pendidikan bervariasi antara $2,93 \%$ sampai dengan 27,6\%. Adapun penyebab dermatofitosis yang dapat dibiakkan di Jakarta adalah Tricophyton rubrum 57,6\%, Epidermophyton floccosum 17,5\%, dan Microsporum canis 9,2\% (Budimulja, 1992 dalam Rahmayani, 2011).

Salah satu penyakit karena dermatofita adalah Tinea pedis.Tinea pedis atau yang sering disebut dengan kutu air merupakan dermatofitosis pada kaki, terutama pada sela-sela jari kaki dan telapak kaki (Septiana, 2015 dalam Muthoharoh et al. 2017). Tinea pedis disebabkan oleh bermacam-macam jenis jamur yaitu Tricophyton rubrum, Tricophyton mentagrophytes dan Epidermophyton floccosum (Kurniati dan Rosita C, 2008). Bila ada infeksi sekunder dapat terjadi otitis eksterna. Penyebab infeksi biasanya jamur kontaminan, yaitu Aspergillus sp., mukor, dan Penisilium. Jamur ini menyerang permukaan tubuh yang terkeratinisasi seperti kulit pada tubuh, kulit yang berambut seperti pada kepala, dan kuku.

Tinea pedis sering menyerang orang dewasa yang bekerja di tempat basah 
seperti tukang cuci, petani atau orang yang setiap hari harus memakai sepatu tertutup. Petani adalah orang yang berprofesi bercocok tanam di sawah, mereka bekerja dari pagi sampei sore di sawah, pada umumnya mereka adalah kaum laki-laki dan perempuan yang berusia 20-60 tahun, karena seringnya mereka berhubungan dengan tempat yang basah dan lembab sehingga mrenyebabkan kaki mereka kelihatan putih dan terkelupas (Rahmayani, 2011).

Untuk mendeteksi jamur penyebab Tinea Pedis ini dapat dilakukan dengan teknik kultur. Pembiakan jamur atau mikroorganisme secara umum di laboratorium dilakukan untuk mempelajari sifat-sifat pertumbuhan yang dimiliki oleh mikroorganisme. Pembiakan ini memerlukan media pertumbuhan yang mengandung nutrien. Pertumbuhan jamur dicirikan dengan sintesis komponen protoplasma yang khas dan berimbang dari nutrien yang terdapat di lingkungannya. Nutrisi digunakan untuk pertumbuhan, sintesis sel, keperluan energi dalam metabolism dan pergerakan. Nutrisi yang dibutuhkan mikroorganisme untuk pertumbuhan meliputi karbon, nitrogen, unsur non logam seperti sulfur dan fosfor, unsur logam seperti $\mathrm{Ca}, \mathrm{Zn}, \mathrm{Na}, \mathrm{K}, \mathrm{Cu}$, $\mathrm{Mn}, \mathrm{Mg}$, dan $\mathrm{Fe}$, vitamin, air, dan energi (Cappucino, 2014).

Media pertumbuhan jamur ini dapat menggunakan bahan alam yang berlimpah di Indonesia sebagai media alternatif pengganti SDA (Sabourand Dextrose Agar). Salah satu bahan alam yang berpotensi sebagai media pertumbuhan adalah bekatul. Bekatul adalah limbah halus yang diperoleh dari proses penggilingan gabah padi. Bekatul dapat di gunakan sebagai substrat untuk menghasilkan enzim. Jenis enzim yang dihasilkan tergantung pada media dan kondisi lingkungan. Pemanfaatan bekatul sebagai media pertumbuhan mikroorganisme didasarkan pada kandungan komponen-komponen nutrisi yang dibutuhkan mikroorganisme (Dewi et al. 2005 dalam Basarang et al. 2016). Hasil penelitian menunjukkan bahwa media bekatul dapat digunakan untuk mengidentifikasi Aspergillus $s p$ dan Candida albicans dari bilasan bronkus penderita tuberkulosis paru (Basarang dan Rianto, 2018). Pertumbuhan Aspergillus niger pada media Bekatul Dextrose lebih cepat dibandingkan pada media Potato Dextrose Agar $(p>0,05)$ tapi tidak berbeda secara signifikan sedangkan jumlah koloni Candida albicans pada media Bekatul Dextrose Agar dan media Potato Dextrose Agar adalah $8,5 \times 10^{5} \mathrm{CFU}$ dan $8,9 \times 10^{5}$ CFU (Basarang, et. al., 2018).

Berdasarkan uraian di atas peneliti tertarik untuk meneliti identifikasi jamur penyebab Tinea pedis pada petani di Kabupaten Gowa menggunakan media bekatul.

\section{METODE PENELITIAN \\ Alat dan Bahan}

Peralatan yang digunakan dalam penelitian ini adalah objek glass, coverglass, batang pengaduk, skapel, mikroskop, pipet tetes, ose, labu Erlenmeyer, hot plate, kapas, aluminium foil, autoklof, termometer, lampu spritus, saringan dan cawan petri.

Adapun bahan yang digunakan dalam penelitian ini adalah Bahan yang digunakan dalam penelitian ini adalah kerokan kulit sela jari kaki petani, $\mathrm{NaCl}$, bekatul, media potato dextrose agar (PDA), akuades, kloramfenikol, agar, dextrose, oil imersi dan laktofenol.

\section{Persiapan Media Bekatul}

Bekatul yang dikumpulkan dari pabrik penggilingan padi. diayak menggunakan saringan. Untuk membuat bekatul, timbang sebanyak 22 gr. direbus didalam $220 \mathrm{ml}$ akuades. Bekatul disaring ke dalam labu Erlenmeyer kemudian ditambahkan agar 4,4 gr, dextrose 4,4 gr dan akuades 4,4 ml. Media bekatul dextrose agar (BDA) dipanaskan di atas hot plate sampai larut sempurna. Diukur $\mathrm{pH}$ 5,6 2. Mulut labu Erlenmeyer disumbat dengan kapas dan aluminium foil 
kemudian disterilkan menggunakan autoklof selama 15 menit pada suhu $121^{\circ} \mathrm{C}$. Setelah proses sterilisasi selesai, media dikeluarkan dari autoklaf. BDA dibiarkan sampai $45-50^{\circ} \mathrm{C}$. Ditambahkan kloramfenikol untuk menghambat pertumbuhan bakteri. Media BDA dituang kedalam cawan petri setril sebanyak 15-20 $\mathrm{ml}$ dan dibiarkan memadat (Basarang dan Rianto, 2018).

\section{Penyiapan Media Potato Dextrose Agar (PDA)}

PDA ditimbang sebanyak 8,58 gr. Media PDA dipanaskan di atas hot plate sampai larut sempurna. Diukur pH 5,6 2 . Mulut labu Erlenmeyer disumbat dengan kapas dan aluminium foil kemudian disterilkan menggunakan autoklof selama 15 menit pada suhu $121^{\circ} \mathrm{C}$. Setelah proses sterilisasi selesai, media dikeluarkan dari autoklaf. PDA dibiarkan sampai $45-50^{\circ} \mathrm{C}$. Ditambahkan kloramfenikol untuk menghambat pertumbuhan bakteri. Media PDA dituang kedalam cawan petri setril sebanyak 15-20 $\mathrm{ml}$ dan dibiarkan memadat.

\section{Pengumpulan Sampel}

Siapkan peralatan yang akan digunakan, kemudian sela jari yang akan dikerok dibersihkan, lalu ambil kerokan kulit dengan menggunakan skapel, hasil kerokan tadi disimpan dalam wadah bersih yang telah disediakan.

\section{Inokulasi Sampel}

Kerokan kulit diinokulasi pada media BDA dan PDA kemudiaan diinkubasi pada suhu $35^{\circ} \mathrm{C}$ selama 2-7 hari.

\section{Pemeriksaan Mikroskopik}

Untuk khamir disiapkan objek glass kemudian ditetesi Aquadest lalu koloni diletakkan diatas objek glass, fiksasi setelah itu tambahkan pewarnaan laktofenol dan tetesi oil imersi. Untuk kapang di tetesi laktofenol, koloni kemudian diletakkan di atas objek glass, lalu tutup dengan cover glass, kemudian periksa di bawah mikroskop dengan pembesaran lensa objektif 40x (Rahmayani, 2011).

\section{Interpretasi hasil}

Dilakukan identifikasi terhadap jamur yang tumbuh. Koloni dan morfologi jamur disesuaikan dengan buku deskripsi jamur medis (Kidd, et.al., 2016).

\section{HASIL DAN PEMBAHASAN}

Berdasarkan hasil pemeriksaan jamur penyebab Tinea pedis yang tumbuh pada media BDA dan PDA dari kerokan jari kaki petani di kabupaten Gowa sebanyak 10 sampel yang telah di lakukakan di laboratorium mikrobiologi Poltekkes Muhammadiyah makassar pada tanggal 20-27 April 2019 diperoleh hasil pemeriksaan pada tabel dibawah ini.

Tabel 4.1. Hasil pemeriksaan jamur penyebab Tinea pedis yang tumbuh pada media BDA dan PDA

\begin{tabular}{ccccc}
\hline \multirow{2}{*}{ Sampel } & \multicolumn{2}{c}{ Dermatofita pada Media } & \multicolumn{2}{c}{$\begin{array}{c}\text { Jamur Lain yang Tumbuh } \\
\text { pada Media }\end{array}$} \\
\cline { 2 - 5 } A & BDA & PDA & \multicolumn{1}{c}{ BDA } & \multicolumn{1}{c}{ PDA } \\
\hline Negatif (-) & Negatif (-) & $\begin{array}{l}\text { Aspergillus } \\
\text { flavus }\end{array}$ & $\begin{array}{l}\text { Aspergillus } \\
\text { flavus dan } \\
\text { khamir }\end{array}$ \\
B & Negatif (-) & Negatif (-) & $\begin{array}{l}\text { Aspergillus } \\
\text { flavus, Mucor } \\
\text { circinelloides } \\
\text { dan } \text { khamir } \\
\text { Khamir dan } \\
\text { Mucor } \\
\text { circinelloides }\end{array}$ & $\begin{array}{l}\text { Mucor } \\
\text { circinelloides } \\
\text { dan Khamir }\end{array}$ \\
Chamir, \\
C
\end{tabular}




\begin{tabular}{|c|c|c|c|c|}
\hline & & & & $\begin{array}{l}\text { Mucor } \\
\text { circinelloides }\end{array}$ \\
\hline D & Negatif (-) & Negatif (-) & $\begin{array}{l}\text { Aspergillus } \\
\text { flavus dan } \\
\text { Khamir }\end{array}$ & $\begin{array}{l}\text { Khamir dan } \\
\text { Mucor } \\
\text { circinelloides }\end{array}$ \\
\hline $\mathrm{E}$ & Negatif (-) & Negatif (-) & $\begin{array}{l}\text { Aspergillus } \\
\text { flavus dan } \\
\text { Mucor } \\
\text { circinelloides }\end{array}$ & Khamir \\
\hline $\mathrm{F}$ & Negatif (-) & Negatif (-) & $\begin{array}{l}\text { Mucor } \\
\text { circinelloides }\end{array}$ & $\begin{array}{l}\text { Khamir dan } \\
\text { Aspergillus } \\
\text { flavus }\end{array}$ \\
\hline G & Negatif (-) & Negatif (-) & $\begin{array}{l}\text { Aspergillus } \\
\text { flavus, Mucor } \\
\text { circinelloides } \\
\text { dan khamir }\end{array}$ & $\begin{array}{l}\text { Mucor } \\
\text { circinelloides } \\
\text { dan khamir }\end{array}$ \\
\hline $\mathrm{H}$ & $\begin{array}{l}\text { Trichophyton } \\
\text { interdigitale }\end{array}$ & $\begin{array}{c}\text { Trichophyton } \\
\text { interdigitale }\end{array}$ & $\begin{array}{l}\text { Aspergillus } \\
\text { flavus dan } \\
\text { Mucor } \\
\text { circinelloides }\end{array}$ & $\begin{array}{l}\text { Aspergillus } \\
\text { flavus dan } \\
\text { Mucor } \\
\text { circinelloides }\end{array}$ \\
\hline I & Negatif (-) & Negatif (-) & $\begin{array}{l}\text { Khamir dan } \\
\text { Mucor } \\
\text { circinelloides }\end{array}$ & $\begin{array}{l}\text { Khamir, Mucor } \\
\text { circinelloides } \\
\text { dan Aspergillus } \\
\text { flavus }\end{array}$ \\
\hline $\mathrm{J}$ & Negatif (-) & Negatif (-) & $\begin{array}{l}\text { Khamir dan } \\
\text { Aspergillus } \\
\text { flavus }\end{array}$ & $\begin{array}{l}\text { Khamir dan } \\
\text { Mucor } \\
\text { circinelloides }\end{array}$ \\
\hline
\end{tabular}

Sumber : Data primer 2019

Untuk tumbuh dan berkembang, jamur membutuhkan nutrien dan faktorfaktor lingkungan yang sesuai. Nutrien berupa unsur-unsur atau senyawa kimia dari lingkungan digunakan sel sebagai konstituen kimia penyusun sel. Secara umum nutrien yang diperlukan dalam bentuk karbon, nitrogen, sulfur, fosfor, kalium, magnesium, natrium, kalsium, nutrien mikro (besi, mangan, zink, kobalt) dan vitamin. Karbon menempati posisi yang unik karena semua organisme hidup memiliki karbon sebagai salah satu senyawa pembangun. Komposisi nutrien ini bisa ditemukan pada bekatul. bekatul yang memiliki kandungan nutrisi bagi kelangsungan hidup jamur sehingga bekatul dapat digunakan untuk mengidentifikasi jamur penyebab Tinea pedis.
Pada penelitian ini petani yang terindikasi menderita Tinea pedis yang diambil kerokan kakinya. berdasarkan ciriciri dan sifat-sifat yang sudah diketahui yaitu kulit terasa gatal dan kulit antara sela-sela jari kaki mengalami maserasi dan sela jari kaki terlihat putih berfisura disertai bau terutama pada jari keempat dan kelima. Sampel yang dikumpulkan kemudian ditanam pada media BDA dan PDA, yang diingkubasi selama 3 hari dilakukan pengamatan jamur yang tumbuh. Dari 10 sampel yang diperiksa di temukan 1 sampel yang Positif jamur Trichophyton interdigitale dan 9 sampel negatif/tidak ditemukan jamur penyebab Tinea pedis tetapi terdapat pertumbuhan jamur yang lain yaitu Aspergillus flavus, Mucor circinelloides, Aspergillus fischeri, dan khamir. 


\begin{abstract}
Menurut Nigam et al. (2019) menyatakan bahwa Trichophyton interdigitale dengan ciri-ciri makroskopiknya yaitu koloni biasanya rata, berwarna putih sampai krem.
\end{abstract} Permukaan bubuk dan pigmen terbalik kekuningan ke coklat kemerahan, sering menjadi merah-coklat yang lebih tua seiring bertambahnya usia. Kemudian dilanjutkan dengan pemeriksaan mikroskopik hifa spiral sesekali dan tidak bulat utuh, dan lebih berlimpah di koloni yang lebih tua. Makrokonidia ramping, dan berdinding halus multiseptat. Positif dalam 7 hari (biasanya 3 sampai 5 hari). Pertumbuhan Trichophyton interdigitale lebih subur pada media BDA dari pada media PDA dengan ditandai ukuran koloni pada media BDA $1,2 \mathrm{~cm}$ dan pada media PDA $0,4 \quad \mathrm{~cm}$. jamur Trichophyton interdigitale terhadap manusia yaitu menyebabkan keratin pada jari kaki.

Apergillus flavus dengan ciri-ciri makroskopiknya yaitu koloni berbentuk butiran, rata, sering dengar alur radial, kuning pada awalnya tetapi dengan cepat menjadi cerah dengan kuning-hijau gelap usia. ciri-ciri makroskopiknya yaitu tampak berdinding kasar, vesikel matang bantalan phialides di seluruh permukaan mereka mereka dan Konidia bersifat globose ke subglobose, mencolok mencolokkan.

Aspergillus fischeri dengan ciri-ciri makroskopiknya yaitu koloninya adalah suede, putih menjadi kuning pucat. Kepala konidial pendek, kolumnar dan uniseriate. Ciri-ciri makroskopiknya yaitu Conidiophore stiped berdinding halus dan vesikel biasanya subglobose untuk berbentuk labu. Conidia globose ke subglobose, halus sampai kasar.

Mucor circinelloides dengan ciriciri makroskopiknya yaitu koloni-koloni berbentuk floccose, pucat keabu-abuan. Ciri-ciri makroskopiknya yaitu Sporangiofor bersifat healin dan sebagian besar bercabang. Sporangiospora besifat hialin, berdinding tipis dan ellipsoidal.
Khamir merupakan kelompok jamur basidiomycetes dan ascomycetes yang mempunyai karakteristik yang unik dan bersifat uniseluler. bentuk khamir sirkuler, permukaan kasar dan warnanya putih susu.

\section{KESIMPULAN}

Berdasarkan penelitian yang telah dilakukan dari 10 sampel kerokan sela jari kaki petani di Kabupaten Gowa dapat disimpulkan bahwa bekatul dapat digunakan untuk media pertumbuhan jamur. Dermatofita penyebab Tinea pedis yang terdapat pada kaki petani yaitu jamur Tricophyton interdigitale. Sedangkan jamur jenis lain adalah Aspergillus flavus, Mucor circinelloides, Aspergillus fischeri, dan khamir.

\section{SARAN}

Disarankan agar petani rajin membersihkan kaki tiap hari, dan menjaga supaya kaki tetap kering khususnya di sela-sela jari kaki. Apabila terjadi infeksi pada sela jari kaki di sarankan agar memakai saleb anti jamur yang diolesi pada kaki, sehingga mengurangi tumbuhnya jamur. Untuk peneliti selanjutnya lebih memperhatikan kualitas bekatul yang digunakan serta tempat penyimpanannya.

\section{DAFTAR PUSTAKA}

Amanah., Sutisna A., Alibasjah R. W. Isolasi dan Identifikasi MikroFungi Dermatofita pada Penderita Tinea Pedis. 2015. (Online) jurnal.unswagati.ac.id. Diakses pada tanggal 18 Januari 2019.

Amiruddin, M. D. 2003. Ilmu Penyakit Kulit. Penerbit Buku: UNHAS. Makassar.

Basarang, M., Rianto, M., R., Magfirah. 2016. Penambahan Glukosa pada Media Bekatul Agar untuk Pertumbuhan Aspergillus sp. Jurnal Medika. (2):56-57.

Basarang, M., Naim, N., Rahmawati. 2018.

Perbandingan 
Pertumbuhan Jamur Pada media Bekatul Dextrose Agar (BDA) dan Potato Dextrose Agar (PDA). (Online) Prosiding Seminar Hasil Penelitian (SNP2M) 2018 (pp.121-125).

Basarang, M., Rianto, M., R. 2018. Pertumbuhan Candida sp dan Aspergillus sp dari Bilasan Bronkus Penderita Tuberkulosis Paru Pada Media Bekatul. (Online) Jurnal Ilmu Alam dan Lingkungan (18):74-82

Basir, S., W . 2015. Akademi Analis Kesehatan Muhammadiyah Makassar. Identifikasi Jamur Pada Kuku Kaki Pemulung di Tempat Pembuangan Akhir (TPA) Tamangapa Kota Makassar. Karya Tulis Ilmiah (KTI) tidak diterbitkan. Makassar: Program Diploma III AKADEMI ANALIS KESEHATAN MUHAMMADIYAH.

Cappucino, J., G., Sherman, N. 2013. Manual Laboratorium Mikrobiologi. Jakarta: Penerbit Buku Kedokteran EGC.

Hadjoeno., Esa T., Nurhayana. Kumpulan Penyakit Infeksi \& Tes Kultur
Senaitivitas Kuman Serta Upaya Pengendaliannya. Surabaya.

Kidd, S., Halliday, C., Alexiou, H., Ellis, D. Description of Medical Fungi. Newstyle Printing. Adelaide.

Magdalena, M. 2018. Hubungan Antara Golongan Darah Sistem ABO Dengan Tinea Korporis dan atau tinea Pedis. Tesis. Fakultas Kedokteran Universitas Sumatera Utara. Medan.

Muthoharoh, A., Sari P.K., Ramadhani, D. 2017. Gambaran Tinea Pedis Pada Sela Jari Kaki Pendulang Intan di Desa Waringin Tunggal RT.07 RW. 04 Kecematan Kuranji Kabupaten Tanah Bumbu. (Online) ejurnal. Repo.stikesborneolestari.ac.id. Diakses pada tanggal 19 Maret 2019.

Rahmayani, 2011. Identifikasi Jamur Suspek Tinea Pedis Pada Sela Jari Kaki Petani di Kelurahan Patte'ne Kabupaten Takalar. Karya Tulis Ilmiah (KTI) tidak diterbitkan. Makassar: Program Diploma III Akademi Analis Kesehatan Muhammadiyah. 